\title{
El MULTICULTURALISMO Y LOS DERECHOS COLECTIVOS EN EL PRIMER CONSTITUCIONALISMO IBEROAMERICANO
}

[Multiculturalism and Collective Rights in the First Latin American Constitutionalism]

\author{
Francisco J. ANDrés SANTOS* \\ Universidad de Valladolid, España \\ Luis Carlos Amezúa Amezúa** \\ Universidad de Valladolid, España
}

\begin{abstract}
RESUMEN
El artículo estudia los mecanismos jurídicos y constitucionales de los que se valieron los Estados iberoamericanos surgidos de la Emancipación para intentar llevar a cabo una integración forzosa de las minorías étnicas en las nuevas repúblicas, sus líneas de continuidad respecto del pasado colonial, y sus flancos débiles que finalmente acabaron llevando a su superación en los recientes desarrollos políticos y constitucionales de América Latina, donde la presencia del elemento indígena ha cobrado un protagonismo político desconocido hasta la fecha. Ello ha de con-
\end{abstract}

\begin{abstract}
This article studies the legal and constitutional mechanisms used by the Latin American Estates that arose from Independence to try to forcefully integrate the ethnic minorities into the new republics, their lines of continuity with respect to the Colonial past and its weaknesses, which eventually led to overcoming them in the recent political and constitutional developments in Latin America, where the presence of indigenous population has taken a political protagonist so far unknown. This must lead us to undertake reflection regarding the alleged existence,
\end{abstract}

ReCibido el 24 de junio y ACEPTADo el 3 de diciembre de 2013

* Catedrático de Derecho Romano de la Universidad de Valladolid. Dirección postal: Facultad de Derecho, Universidad de Valladolid, Plaza de la Universidad s/n, 47002 Valladolid, España. Correo electrónico: fjandres@der.uva.es

** Doctor en Derecho, ayudante de Filosofía del Derecho. Dirección postal: Facultad de Derecho de la Universidad de Valladolid, Plaza de la Universidad s/n, 47002 Valladolid, España. Correo electrónico: amezua@der.uva.es 
ducirnos a realizar una reflexión en torno a la supuesta existencia, validez y sentido de los llamados "derechos colectivos" y hasta qué punto estos suponen una pieza indispensable para la ordenación jurídica de sociedades multiculturales complejas en este mundo globalizado.

\section{Palabras Clave}

Independencia iberoamericana Minorías étnico-culturales - Integración - Constitución - Multiculturalismo Derechos colectivos. validity and sense of the so-called "collective rights" and regarding to which extent they are a crucial piece for the legal systems of complex multicultural societies in this globalized world.

\section{KeYwORDS}

Latin American Independence Ethnic-Cultural Minorities - Integration - Constitution - Multiculturalism - Collective Rights.

\section{INTRODUCCIÓN ${ }^{1}$}

La celebración en estos últimos años del Bicentenario del inicio del proceso de independencia o Emancipación de los Estados iberoamericanos nos brinda una excelente oportunidad para reflexionar sobre una ardua cuestión que se encuentra firmemente encallada en el núcleo de los modernos Estados de Derecho -o, mejor aún, de las actuales sociedades democráticas-, cual es el hecho de la presencia en su seno de una pluralidad de elementos étnicos -o, más bien, culturales- que contrasta con la visión monolítica de la ciudadanía que se desprende de la literalidad de la mayor parte de las Constituciones democráticas. Se trata de un "problema" -si es que como tal quiere observarse- que, a medida que el proceso globalizador al que asistimos en los últimos decenios avanza irremisiblemente, va caracterizando a todas las sociedades democráticas modernas y provoca desafíos de gran calado que afectan de lleno al corazón de la doctrina tradicional de los derechos humanos, enfocada desde sus orígenes a partir de una óptica más bien monocultural, cuando no, directamente, eurocéntrica. Pero, si bien este hecho en muchos lugares - por ejemplo, en la sociedad española- resulta de algún

\footnotetext{
${ }^{1}$ Este trabajo se enmarca entre las actividades del Proyecto de Investigación titulado "Influencias del pensamiento hispánico de la primera modernidad en el discurso jurídico y político de la Emancipación americana" (Investigador principal: Dr. Javier Peña Echeverría), subvencionado por la Junta de Castilla y León (referencia VA 010A101). Parte de este trabajo ha podido realizarse gracias a una estancia de investigación de F. J. Andrés Santos en el Max-Planck-Institut für europäische Rechtsgeschichte de Frankfurt am Main (Alemania) en otoño de 2011, por lo que queremos dar aquí las gracias a dicha institución.
} 
modo un fenómeno nuevo, en cambio en otros ámbitos, como es el caso de los Estados latinoamericanos, constituye un elemento nuclear de su organización sociopolítica desde sus mismos inicios como entidades políticamente independientes y ya con anterioridad a su constitución como tales. De ahí, por tanto, que verter una mirada sobre los procesos a través de los cuales esos Estados latinoamericanos afrontaron la cuestión desde sus mismos orígenes tal vez pueda aportarnos algunas lecciones útiles a la hora de ver cómo se ha diseñado la arquitectura de la moderna teoría de los derechos humanos, que por necesidad se ha debido producir históricamente y conforme a unos parámetros dictados por circunstancias históricas concretas, si bien al mismo tiempo estas se han visto mediatizadas a menudo por ideologías o convicciones dominantes en un momento dado, como tendremos ocasión de ver. Ello ha de llevarnos forzosamente a efectuar una reflexión en torno a la supuesta existencia de los llamados "derechos (humanos) colectivos" (una categoría técnico-jurídica, pero sobre todo filosófico-política de gran relevancia en los últimos tiempos, como han puesto de relieve autores como Will Kymlicka, Charles Taylor, Jacob Levy o Rainer Bauböck) y hasta qué punto estos suponen una pieza indispensable para la ordenación jurídica de sociedades multiculturales complejas en este mundo globalizado ${ }^{2}$.

\section{EL MODELO COLONIAL: PATERNALISMO Y SEPARACIÓN}

En efecto, la Conquista y Colonización de América por parte de las potencias ibéricas supuso la puesta en práctica de un experimento social consistente en la trasposición al Nuevo Continente de las estructuras sociales, políticas y jurídicas del "Ancien Régime” europeo, en un contexto ecológico

${ }^{2}$ No es nuestra intención entrar a analizar aquí este concepto y sus complejas estribaciones actuales, porque ello nos alejaría del objetivo fundamental de estas notas. Entendemos, sin embargo, que las indagaciones de tipo histórico-conceptual como la que aquí proponemos puede contribuir a aclarar el significado de este controvertido sintagma. Sobre el tema la bibliografía es muy amplia; solo a modo de ejemplo, véanse: López CAlera, Nicolás, ¿Hay derechos colectivos? Individualidad y socialidad en la teoría de los derechos (Barcelona, 2000); AnSUÁtegui Roig, Francisco Javier (editor), Una discusión sobre los derechos colectivos (Madrid, 2001); Clavero, Bartolomé, Derechos humanos (individuales) y Derechos históricos (colectivos), en HerRero DE MiÑón, Miguel - Lluch, Ernest (editores), Derechos históricos y constitucionalismo útil (Barcelona, 2001); Cruz PArCero, Juan Antonio, Sobre el concepto de derechos colectivos, en El Mismo, El lenguaje de los derechos. Ensayo para una teoría estructural de los derechos (Madrid, 2007), pp. 101-126; Jones, Peter, Group Rights, en Zalta, Edward N. (editor), The Stanford Enciclopedia of Philosophy (2008) [http://plato. stanford.edu/entries/rights-group] (con amplia bibliografía internacional) [1 de julio de 2012]. 
y cultural completamente distinto de aquel en que ese modelo se forjó y venía desarrollándose desde mucho tiempo atrás. En concreto, los colonizadores hubieron de hacer frente al hecho trascendental de la convivencia con una serie de pueblos de historia, tradición y cultura completamente ajenas a las de la tradición europea, y a menudo refractarias a esta, y tuvieron que idear, por tanto, mecanismos de convivencia e integración de esos pueblos en el espacio político organizado y dominado por la Monarquía Hispánica. A partir de la crítica a los aspectos más sórdidos y destructivos de la Conquista realizada por un sector de la Iglesia Católica, y la consiguiente asunción de responsabilidades por parte de la Monarquía plasmada en las llamadas "Leyes de Burgos" (1512) -y, posteriormente, en las llamadas "Leyes Nuevas" $(1542)^{3}$-, la justificación ideológica de la Conquista y Colonización por los europeos pasó a ser la idea de la sumisión voluntaria por parte de esos pueblos a la soberanía del rey de Castilla (de ahí la importancia de la discusión en torno al tema de la servidumbre voluntaria en la literatura política y jurídica de la época colonial). Así, por ejemplo, el teólogo mexicano Alonso de Veracruz (1507-1584), en su obra De dominio infidelium et iusto bello (1553-1556) $)^{4}$ señalaba que el título definitivo que legitima la dominación del rey de España sobre los territorios americanos es la libre sumisión de los pueblos indígenas: la aceptación y sumisión de los pueblos indios a los conquistadores solo podía ser válida si no era consecuencia del miedo y la coacción, y si la transferencia de soberanía se hacía por la libre voluntad y consentimiento del señor legítimo y de la comunidad india 5 . Esto implicaba como consecuencia necesaria el reconocimiento por parte del soberano del "derecho" de los indios a su propia identidad nacional (una suerte de "derecho de autodeterminación"), siempre dentro del marco "protector", de la "tutela", de la Monarquía Hispánica (como correspondía a pueblos considerados inferiores en desarrollo, pero dotados de naturaleza y dignidad humanas y, por tanto, de libertad y capacidad jurídica, una idea que quedó perfectamente codificada a través de la doctrina vitoriana). En este sentido,

${ }^{3} \mathrm{Al}$ respecto, véanse últimamente: MARTínez, Felicísimo - Mate, Reyes - Ruiz, Marcos R. (coordinadores), Pensar Europa desde América. Un acontecimiento que cambió el mundo (Barcelona, 2012); Szaszdi León-Borja, István, Después de las Leyes de Burgos, en e-Legal History Review, 14 (2012) [www.iustel.com]; SÁNCHEZ Domingo, Rafael, Las Leyes de Burgos y la doctrina jurídica de la Conquista, en Revista Jurídica de Castilla y León, 28 (2012), pp. 204-258 (descargable en: <http://www.jcyl. es/junta/cp/boletin/Revista_Juridica_28.pdf $>$ ).

${ }^{4}$ Burrus, Ernest J. (editor), The Writings of Alonso de la Vera Cruz, II: Defense of the Indians: Their Rights (Rome St. Louis, Mo., 1968).

${ }^{5}$ De dominio infidelium et iusto bello, quaestio 11a, núm. 863 ss. (ed. E. J. Burrus, pp. 433 ss.). 
significativamente, el catedrático de Lima José de Acosta (1540-1600) ${ }^{6}$, un intelectual "orgánico" muy próximo a la corte del rey Felipe II, reivindicaba el derecho de los indios a su identidad nacional; para protegerla, exigía que la Corona conservara y promocionara las tradiciones de los indios y sus costumbre patrias, sus fueros y leyes municipales ${ }^{7}$; pero al mismo tiempo era partidario de que el rey de España hiciera que en su imperio de las Indias todos hablasen una sola lengua o, al menos, que el castellano fuera la única lengua oficial en todas partes, si bien, contradictoriamente, reconocía el derecho de los pueblos indios a no renunciar a su propia identidad cultural y lingüística ${ }^{8}$. En consecuencia, se concibió la existencia en el seno de un mismo espacio político de dos comunidades jurídica y culturalmente diferenciadas, la "república de los españoles" y la "república de los indios", dotadas de diferentes estructuras organizativas y solo unidas por la común sujeción a un soberano distante9. Esto venía facilitado por el hecho de que la monarquía había establecido que solo se observasen en las Indias las leyes de Castilla, pero el propio Derecho castellano admitía que sobre las leyes prevalecieran las costumbres, que en el contexto americano cabía perfectamente que fueran las indígenas, siempre y cuando, claro está, que tales costumbres no atentasen contra la religión cristiana y estuvieran sujetas a la gracia del monarca ${ }^{10}$. En consecuencia, el dominio podía imponerse sin comportar por ello una ruptura radical o una extirpación del Derecho indígena y, por consiguiente, una destrucción aún mayor de la sociedad india prehispánica. Con todo, a pesar de ese formal reconocimiento del libre desarrollo de esos pueblos, la dinámica de la organización del poder de la Monarquía absoluta hacía esencialmente imposible cualquier aceptación real de una auténtica "constituyencia" ("constituency") - entendiendo por tal una cultura popular capaz de establecer una legitimidad constitucional que garantice una

${ }^{6}$ Véase al respecto: PAgden, Anthony, La caída del hombre natural (1986, trad. esp. Madrid, 1988) pp. 201 ss.

${ }^{7}$ De procuranda Indorum salute (Salamanca, 1588), lib. III, cap. $2^{\circ}$ (ed. L. Pereña Abril y otros, Madrid, 1984), I, p. 397).

${ }^{8}$ De procuranda Indorum salute, lib. IV cap. $2^{\circ}$ (ed. L. Pereña Abril y otros, Madrid, 1984) II, pp. 63 ss.

${ }^{9}$ Véase al respecto: Gareis, Iris, 'República de indios' - 'República de españoles': reinterpretación actual de conceptos andinos coloniales, en Jabrbuch für Geschichte von Staat, Wirtschaft und Gesellschaft Lateinamerikas, 30 (1993), pp. 259-277; A. LeVaggi, Abelardo, República de indios y república de españoles en los reinos de Indias, en Revista de Estudios Histórico-Jurídicos, 23 (2001), pp. 419-428.

${ }^{10}$ Barrientos Grandón, Javier, Historia del Derecho indiano del Descubrimiento colombino a la Codificación, I: Ius commune - ius proprium en las Indias Occidentales (Roma, 2000), pp. 352 ss. 
serie de derechos civiles y libertades públicas ${ }^{11}$ de los pueblos indígenas, del mismo modo que privaba de espacios de decisión libre a los propios criollos asentados en esos mismos territorios.

\section{EL MOMENTO CONSTITUCIONAL: "SLAM INCLUSION" FRENTE A EXCLUSIÓN Y AUTODETERMINACIÓN}

La emergencia de los Estados constitucionales surgidos del proceso de Emancipación iberoamericana a inicios del siglo XIX hubo de enfrentarse a este problema. Las nuevas constituciones trataron de importar modelos europeos adoptados a partir de una síntesis entre la tradición hispánica del Antiguo Régimen y los nuevos aires del liberalismo ilustrado. Pero la consecuencia de la implantación de este nuevo modelo organizativo sustitutivo de la Monarquía Hispánica no fue ni un verdadero reconocimiento del supuesto "derecho a la autodeterminación" de los pueblos indígenas, ni tampoco una directa exclusión de estos pueblos del conjunto de la ciudadanía (según el modelo de los Estados Unidos), sino una suerte de "integración forzada" ("slam inclusión") de estos pueblos en el seno de los nuevos Estados constitucionales a un nivel atomista, o sea, en tanto que conjuntos de individuos y no de pueblos ${ }^{12}$. Es decir, se trataba de consagrar la ficción de que estos pueblos se integraban en condiciones de estricta igualdad en una comunidad política unitaria dominada, de hecho, social e ideológicamente por un solo sector (generalmente minoritario) de la población, es decir, la minoría criolla.

Efectivamente, los nuevos Estados surgidos de la descomposición de los Imperios ibéricos vinieron a configurarse - continuando de hecho categorías mentales y estructuras políticas generadas en la metrópoli - conforme al modelo vatteliano ${ }^{13}$ de Estado postwestfalliano, esto es, un concepto en virtud del cual el único sujeto de las relaciones de poder supraindividuales es el Estado, identificado además con la Nación como términos perfectamente intercambiables. A diferencia del modelo iusnaturalista católico anterior dominante en el contexto hispánico, este modelo vatteliano -siguiendo en realidad los pasos marcados por Hobbes- se basa en la dicotomía Estado/

${ }^{11}$ Clavero, Bartolomé, Ama Llunku, Abya Yala: Constituyencia Indígena y Código Ladino por América (Madrid, 2000), p. 15.

${ }^{12}$ Qujudda, Mónica, Estado nacional y pueblos originarios, entre la homogenización y la diversidad: ¿una pulsión colectiva duradera?, en Giraudo, Laura (editora), Ciudadanía y derechos indigenas en América Latina: poblaciones, estados y orden internacional (Madrid, 2007), pp. 59-81.

${ }^{13}$ Nos referimos, claro está, al modelo descrito en la influyente obra de Emeric DE Vattel, Le droit des gens ou Principes de la loi naturelle appliqués à la conduite et aux affaires des Nations et des Souverains (Londres, 1758), 2 vols. 
individuo, que reconoce los derechos de los individuos, por una parte, y la soberanía del colectivo social completo, por la otra. Esta construcción no presta atención, sin embargo, a la gran variedad de formas de asociación intermedias o alternativas que pueden encontrarse en las culturas humanas - particularmente en una realidad tan compleja como era la americana de finales de la Edad Moderna-, ni está ideada para adscribir a dichos grupos otros derechos que los que puedan deducirse de las libertades del individuo o de las prerrogativas del Estado. La convergencia entre los conceptos de Estado y Nación en este esquema no es sino un corolario lógico de la dicotomía Estado/Individuo, en la medida en que en este modelo no se reconocen realidades intermedias y, por tanto, no pueden marcarse diferencias conceptuales entre diversos términos de agregación de individuos. No se concibe la idea de que puedan existir naciones diversas en el interior de un Estado, por la sencilla razón de que entre Estado y nación debe haber una correspondencia unívoca (pero aún no biunívoca en ese momento histórico). Las comunidades subyacentes al cuerpo social constituido como Estado están abocadas, pues, a su disolución en el seno de esa entidad colectiva única, y no cabe, por tanto, hablar de derechos entendidos como atributos propios de tales comunidades ${ }^{14}$.

Esta visión vatteliana del Derecho de gentes y las relaciones intra e internacionales tuvo un gran impacto en el pensamiento liberal europeo y marcó naturalmente los planteamientos teóricos de los ideólogos de la Emancipación americana, que por supuesto experimentaron una positivación en el campo del Derecho constitucional. Los independentistas americanos en esto no hicieron sino trasladar a su terreno valores subyacentes a las formas europeas de organización social y política, produciendo como resultado natural una continuación de los esquemas del colonialismo bajo el designio del momento constitucional. En realidad, el modelo último de las primeras Constituciones independentistas iberoamericanas fue la propia Constitución de Cádiz $(1812)^{15}$, que parte de la premisa de que la Nación española es la reunión de todos los españoles de ambos hemisferios (artículo 1), considerando como españoles a "todos los hombres libres nacidos y avecindados en los dominios de las Españas, y los hijos de estos" (artículo 5) (adviértase el uso del plural). Es decir, a efectos constitucionales, los indígenas americanos se consideraban

${ }^{14}$ Véase al respecto: Anaya, James S., Los pueblos indigenas en el Derecho internacional (Madrid, 2005), pp. 48 ss.

${ }^{15}$ Chust, Manuel (coordinador), Doceañismos, constituciones e independencias. La Constitución de 1812 y América (Madrid, 2006); El mismo, La Constitución de 1812: una revolución constitucional bihemisférica, en Annino, Antonio - Ternavasio, Marcela (coordinadores), El laboratorio constitucional iberoamericano: 1807/18081830 (Madrid - Frankfurt am Main, 2012), pp. 93-114. 
perfectamente españoles, igual que los criollos, esto es, pasaban a integrarse indiferenciadamente en una ciudadanía común. La única referencia explícita a la humanidad indígena en la Constitución de Cádiz se encuentra en su artículo 335, inciso 10': "Las Diputaciones de las provincias de Ultramar velarán sobre la economia, orden y progresos de las misiones para la conversión de los indios infieles, cuyos encargados les darán razón de sus operaciones en este ramo, para que se eviten los abusos: todo lo que las Diputaciones pondrán en noticia del Gobierno". Evidentemente es un texto en el que se prorrogan las condiciones de supremacía del dominio colonial español sobre el territorio americano $^{16}$, justificado ideológicamente por las necesidades de extensión de la fe cristiana a todos los pueblos de la tierra, conforme a las coordenadas marcadas por el pensamiento escolástico. En consecuencia, se establecía en la Constitución una previsión de incorporación a la ciudadanía bajo dichos supuestos de supremacía que prolongaban el signo del colonialismo. Por regla general, se consideraba que dicha integración ciudadana se producía ya en virtud automática de la misma Constitución, pero reducido su espacio de autonomía al ámbito local y sin ninguna posibilidad de hacer valer, y menos aún desarrollar, su Derecho tradicional ante la jurisdicción ordinaria, habida cuenta de la previsión constitucional que establecía la existencia de un solo fuero en las causa civiles y criminales para toda clase de personas (artículo 248) y la necesidad de proveer de un solo Código de Derecho civil, criminal y de comercio para toda la Monarquía (artículo 258), así como la potestad exclusiva de los tribunales estatales para aplicar las leyes en causas civiles y criminales (artículos 17 y 242).

La aplicación de la Constitución en los territorios americanos, en la medida en que tuvo lugar (más en México, donde estuvo en vigor transitoriamente incluso después de la independencia, hasta 1824, pero también en Centroamérica, en Perú o en Bolivia) ${ }^{17}$ tuvo unos efectos inesperados. Los pueblos indígenas comenzaron a adoptar el sistema constitucional a nivel municipal, pero duplicando las instituciones, las propias y las sobrevenidas a través de las elecciones locales, como cobertura para la conservación y reforzamiento no sólo del Derecho consuetudinario y las autoridades comunitarias, sino también de la pertenencia a los pueblos en el sentido de sujetos territoriales de culturas indígenas. A través de la participación en los derechos políticos limitados que confería el constitucionalismo gaditano, la ciudadanía indígena no parecía resignarse al espacio municipal asignado. Se trató, en suma, de un movimiento imprevisible, ya que el mecanismo constitucional no garantizaba

\footnotetext{
${ }^{16}$ Clavero, Bartolomé, Ama Llunku, Abya Yala, cit. (n. 11), pp. 82 ss.

${ }^{17}$ Ramos Santana, Alberto (editor), La Constitución de Cádiz y su buella en América (Cádiz, 2011).
} 
cálculo ni control, lo que llegó a alarmar a los criollos y pudo tener que ver con el impulso por parte de estos hacia la independencia ${ }^{18}$.

Los nuevos Estados reprodujeron el modelo gaditano, pero con un sentido aún más compacto, como se observa a través de sus primeras constituciones. La Nueva Granada (luego Gran Colombia) probó a constituirse a través del "Acta de la Federación" de $1811^{19}$, en la que, respecto a los pueblos indígenas ${ }^{20}$, se ofrece una apreciación contradictoria que tiene su lógica: se entendía que, a los efectos constitucionales, todos los sometidos hasta entonces al dominio hispano pasaban a integrar indiferenciadamente la ciudadanía en común con los criollos; pero el territorio restante, el de aquellos pueblos hasta entonces resistentes, se consideraba res nullius, tierras jurídicamente de nadie "por estar inhabitadas" (artículo 23), sin perjuicio de que a continuación se diga en relación con su población que "no por esto se despojará ni se hará la menor vejación o agravio a las tribus errantes o naciones de indios bárbaros que se hallen situadas o establecidas dentro de dichos territorios; antes bien se las respetará como legitimos y antiguos propietarios, proporcionándoles el beneficio de la civilización y religión por medio del comercio y por todas aquellas vias suaves que aconseja la razón y dicta la caridad cristiana, y que solo son propias de un pueblo civilizado y culto; a menos que sus hostilidades nos obliguen a otra cosa" (artículo 24); y asimismo que "porla misma razón podremos entrar en tratados y negociaciones con ellos sobre esos objetos, protegiendo sus derechos con toda la bumanidady filosofia que demanda su actual imbecilidad, y la consideración de los males que ya les causó, sin culpa suya, una nación conquistadora" (artículo 25). Es decir, como puede verse, hay una sustancial continuidad, incluso en el lenguaje utilizado, con la lógica colonial en el momento constitucional, atribuyéndose una parte de la nueva ciudadanía (la no indígena) el poder de definir los derechos correspondientes de un modo que al mismo tiempo los concede a la otra parte, por su evidente humanidad, pero a la vez se los sustrae, por su presunta barbarie ${ }^{21}$.

${ }^{18}$ LynCH, John, The Spanish American Revolutions 1808-1826 (London, 1973), p. $341 \mathrm{~s}$.

${ }^{19}$ Restrepo Piedrahita, Carlos, Las primeras constituciones politicas de Colombia y Venezuela, en Soberanes Fernández, José Luis (editor), El primer constitucionalismo iberoamericano (Madrid, 1992 = AYER. 8, 1992), pp. 75-146, 97 ss.; ThiBaud, Clément, En busca de la república federal: el primer constitucionalismo en la Nueva Granada, en Annino, Antonio - Ternavasio, Marcela (coordinadores), cit. (n. 15), pp. 35-54.

${ }^{20}$ Almario García, Óscar, Del nacionalismo americano en las Cortes de Cádiz al independentismo y nacionalismo de Estado en la Nueva Granada, 1808-1821, en Chust, Manuel - Fraseuet, Ivana (editores), Los colores de las independencias iberoamericanas. Liberalismo, etnia y raza (Madrid, 2009), pp. 199-219.

${ }^{21}$ Clavero, Bartolomé, Constituciones y pueblos entre Cádiz y México, Europa 
Del mismo modo la Constitución de Venezuela de $1811^{22}$, partiendo de una común ciudadanía de criollos e indígenas, añade un apéndice (artículo 200) en virtud del cual se establece que: "Como la parte de ciudadanos que hasta hoy se han denominado Indios, no han conseguido el fruto apreciable de algunas leyes que la Monarquía Española dictó a su favor, porque los encargados del gobierno en estos paises tenían olvidada su ejecución; y como las basas del sistema de gobierno que en esta Constitución ha adoptado Venezuela, no son otras que la de la justicia y la igualdad, encarga muy particularmente a los Gobiernos provinciales, que asi como han de aplicar sus fatigas y cuidados para conseguir la ilustración de todos los habitantes del Estado, proporcionarles escuelas, academias y colegios en donde aprendan todos los que quieran losprincipios de Religión, de la sana moral, de la política, de las ciencias y artes útiles y necesarias para el sostenimiento y prosperidad de los pueblos, procuren por todos los medios posibles atraer a los referidos ciudadanos naturales a estas casa de ilustración y enseñanza, hacerles comprehender la intima unión que tiene con todos los demás ciudadanos, las consideraciones que como aquellos merecen del Gobierno y los derechos de que gozan por el solo hecho de ser hombres iguales a todos los de su especie, a fin de conseguir por este medio sacarlos del abatimiento y rusticidad en que los ha mantenido el antiguo estado de cosas y que no permanezcan por más tiempo aislados y aun temerosos de tratar a los demás hombres; probibiendo desde ahora que puedan aplicarse involuntariamente a prestar sus servicios a Tenientes o Curas de sus parroquias, ni a otra persona alguna y permitiéndoles el reparto en propiedad de las tierras que les estaban concedidas y de que están en posesión, para que a proporción entre los padres de familia de cada pueblo, las dividan y dispongan de ellas como verdaderos señores, según los términos y reglamentos que formen los Gobiernos provinciales".

Esto significa, en definitiva, un programa colonial en toda línea dirigido a la transformación de la mayoría por la minoría en virtud de una pretensión supremacista de esta sobre aquella en nombre de una presunta superioridad civilizatoria $^{23}$ : nada muy distinto, por tanto, del modelo vitoriano de la Mo-

y América, en Clavero, Bartolomé - Portillo, José María - Lorente, Marta, Pueblos, nación, constitución (en torno a 1812) (Vitoria/Gasteiz, 2004), pp. 11-51, pp. $30 \mathrm{s.}$

${ }^{22}$ Restrepo Piedrahita, Carlos, Lasprimeras constitucionespolíticas de Colombia y Venezuela, cit. (n. 19), pp. 90 ss.; Quintero, Inés - Almazara, Ángel Rafael, Dos proyectos: un solo territorio. Constitucionalismo, soberanía y representación. Venezuela, 1808-1821, en Annino, Antonio - Ternavasio, Marcela (coordinadores), cit. (n. 15), pp. 55-70.

${ }^{23}$ Clavero, Bartolomé, Constituciones y pueblos entre Cádiz y México, Europa y América, en Chust, Manuel (coordinador), Doceañismos, cit. (n. 15), pp. 31 ss.; EL MISMo, De pueblos, constituciones y no se sabe si de nación, en torno a 1812, cit. (n. 21), pp. $15-31,25$. 
narquía hispánica, pero sin el reconocimiento de la existencia real de una diferencia jurídica susceptible de ser conservada.

Como un último ejemplo de estas tempranas Constituciones independentistas iberoamericanas podemos mencionar el caso de México $^{24}$. Este mantuvo, como hemos dicho, la vigencia provisional de la Constitución gaditana hasta la aprobación de una Constitución federal en $1824^{25}$. Mientras tanto, diversos Estados de la Federación fueron aprobando sus propias Constituciones de nivel estatal, en todas las cuales la minoría criolla se organizó para evitar que la mayoría indígena cobrara poder sobre su propio terreno. Tanto los Estados como la Federación mantuvieron una concepción incluyente de la ciudadanía, es decir, una ciudadanía común de criollos e indígenas, única e indivisible. Pero la perspectiva federal solo se abrió a subconjuntos de esa ciudadanía común abstractamente definidos, no a los grupos humanos constituidos étnica o culturalmente. En ningún caso se admitió la constitución formal como Estado federado de ningún pueblo indígena; la respuesta ante el caso hipotético era la guerra, reputada unilateralmente como legítima (es decir, como corresponde al paradigma colonial de represión violenta del resistente al poder legal de la potencia conquistadora). El Estado de Chiapas, por ejemplo, en su Constitución de 1826, permitió la acumulación de funciones de los "jefes políticos" (i.e. representantes del Gobierno del Estado en los territorios locales) y los “alcaldes constitucionales" (i.e. autoridades municipales elegidas en elecciones locales, en su mayoría indígenas), lo que significaba en la práctica la suspensión de los derechos políticos de la ciudadanía indígena, ante el temor criollo por su superioridad numérica. Asimismo la Constitución del Estado de Occidente, de 1825, estableció la suspensión de derechos del ciudadano indígena "por tener costumbre de andar vergonzosamente desnudo" o también "por incapacidad física o moral, notoria o calificada por la autoridad competente" (criolla, por supuesto, añadimos nosotros). De igual manera, en el Estado de Yucatán, en 1825, los mestizos tomaron el control de los consejos municipales como presidentes o secretarios de los nuevos cuerpos colegiales, y quitaron a los indígenas toda posibilidad de participar activamente en la toma de decisiones ${ }^{26}$. Se trata, por tanto,

${ }^{24}$ VAn Young, Eric, Etnia, politica local e insurgencia en México, 1810-1821, en Chust, Manuel - Fraseuet, Ivana (editores), Los colores de las independencias iberoamericanas, cit. (n. 20), pp. 143-169. Con una perspectiva más amplia: GoNZÁLEZ Galván, Jorge Alberto, El Estado, los indigenas y el Derecho (México, 2010).

${ }^{25}$ Soberanes Fernández, José Luis, El primer constitucionalismo mexicano, en El Mismo (editor), El primer constitucionalismo iberoamericano, cit. (n. 19), pp. 1744; Fras euet, Ivana, Orígenes del primer constitucionalismo mexicano, 1810-1824, en Annino, Antonio - Ternavasio, Marcela (coordinadores), cit. (n. 15), pp. 115-134.

${ }^{26}$ Álvarez Cuartero, Izaskun, Hacer patria sin indios. De los sanjuanistas a la 
de la imposición de prejuicios supremacistas de la parte constituyente, que es la no indígena, y que permite su fácil extensión a colectividades enteras aun con la formulación individualista propia del lenguaje del primer constitucionalismo liberal. La inclusión ciudadana de los pueblos indígenas en el primer momento constitucional resultaba, por tanto, tan condicional como onerosa, como apunta acertadamente Bartolomé Clavero ${ }^{27}$. Como significativa piedra de toque al respecto puede señalarse, por fin, el hecho de que todas estas Constituciones -las de México y todas las demás- aparecen redactadas exclusivamente en castellano, la única lengua reconocida como oficial, aunque las indígenas pudieran ser toleradas como consecuencia de la pura imposición social ${ }^{28}$.

\section{CONCLUSIÓN:}

\section{LA EMERGENCIA DE LOS DERECHOS COLECTIVOS, ¿UN MAL} NECESARIO?

A lo largo de la segunda mitad del siglo XIX y primera mitad del siglo XX este modelo vatteliano de Estado y esta concepción monolítica de la ciudadanía fue entrando en crisis a nivel mundial, abriéndose paso un nuevo paradigma constitucional de corte pluralista ${ }^{29}$. Pero en América Latina es sobre todo en la segunda mitad del siglo XX, con la crisis del modelo liberal, autoritario y agroexportador característico del Estado criollo iberoamericano y la necesidad de generar un nuevo modelo productivo, cuando va a surgir la necesidad de cuestionar y reformar este modo de afrontar el "problema indígena” (que, huelga decirlo, no fue resuelto por la vía de la integración forzosa $-\mathrm{y}$, por consiguiente, falsa- ensayada hasta entonces) $)^{30}$. Un nuevo

guerra de castas, 1812-1847, en CHust, Manuel - FrasQuet, Ivana (editores), Los colores de las independencias iberoamericanas, cit. (n. 20), pp. 171-196, 190.

${ }^{27}$ Clavero, Bartolomé, Constituciones y pueblos entre Cádiz y México, Europa y América, cit. (n. 21), p. 42; para un desarrollo más detallado, véase El mismo, Ama Llunku, Abya Yala, cit. (n. 11), pp. 113 ss.

${ }^{28}$ Clavero, Barcelona, Multiculturalismo y monoconstitucionalismo de lengua castellana en América, en EL mismo, "Happy Constitution". Cultura y lengua constitucionales (Madrid, 1997), pp. 237-268.

${ }^{29} \mathrm{Al}$ respecto, véase últimamente: Martínez De BRINGas, Asier, Derechos humanos y diversidad(es) cultural(es). Los retos de la interculturalidad, en Derechos y Libertades, 26 (2012), pp. 109-144.

${ }^{30}$ GiRAUdo, Laura, Entre rupturas y retornos: la nueva cuestión indigena en América Latina, en La misma (editora), Ciudadania y derechos indigenas en América Latina, cit. (n. 12), pp. 7-57; Amry, René Paul, Defensa cultural y pueblos indigenas: propuestas para la actualización del debate, en Hurtado Pozo, José (director), Derecho penal y pluralidad cultural, en Anuario de Derecho Penal 2006 (Lima, 2007), pp. 73-100; más 
pensamiento indigenista comenzó a enfocar el "problema indígena" como social y cultural en vez de racial, y se distanció de las políticas de asimilación forzosa practicadas en la época anterior. Las nuevas constituciones han ido estableciendo un marco de reconocimiento de la pluralidad étnica y cultural en el seno de los Estados americanos que tiene sus repercusiones también de alcance jurídico. Los Estados no solo se limitan a admitir el uso como lenguas co-oficiales de las lenguas indígenas, o a comprometerse a dotar de espacios propios a los pueblos indígenas en los que puedan desarrollar sus tradiciones culturales y sus modos de producción, sino que incluso llegan a reconocer su carácter multicultural y plurinacional, y, en consecuencia, a admitir en muchos casos la posibilidad de que los pueblos indígenas conserven y desarrollen sus sistemas tradicionales de organización social y su derecho consuetudinario $^{31}$. No se trata solo del reconocimiento del derecho a la identidad cultural, sino que, más aún, se dan pasos en la dirección del reconocimiento del derecho a la "libre determinación" de esos pueblos, es decir, en la línea de las declaraciones internacionales de derechos posteriores al año 1960 , en que las Naciones Unidas proclamaron la ilicitud del colonialismo y el derecho de los pueblos a la propia emancipación. A partir de ese momento comienza a hablarse en este sentido de la aparición de un derecho humano de carácter colectivo, donde surge un nuevo tipo de sujeto de derecho que rompe con la dicotomía del modelo vatteliano: ese nuevo sujeto de derecho serían los "pueblos" ${ }^{32}$, entendidos como agregaciones humanas que poseen unos elementos de cohesión prepolíticos (es decir, culturales) y que no necesitan constituirse como Estados (es decir, no necesitan de una constitución como tal) para presentar una existencia diferenciada y exenta de cualesquiera otras entidades y reclamar derechos en cuanto tales. Se entiende que el derecho de cada pueblo a la libertad colectiva es un requisito necesario para la libertad individual, es decir, para los espacios de libertad de unos seres cuya vida y su propia individualidad no surge ni se desarrolla en el seno de una humanidad indiferenciada, sino en culturas propias y particulares de índole nacional o comunitaria.

La traslación de este modelo a los pueblos indígenas ha sido, sin embargo, puesta en cuestión por varios conceptos ${ }^{33}: i$ ) por un lado, porque las

detalles, últimamente, en: CABEdo Mallol, Vicente, Pluralismo jurídico y pueblos indigenas (Barcelona, 2012). Abundante información actualizada puede encontrarse en: http://clavero.derechosindigenas.org

${ }^{31}$ Cabedo Mallol, Laura, cit. (n. 30), pp. 51 ss.

${ }^{32}$ Clavero, Bartolomé, Derechos humanos (individuales) y Derechos históricos (colectivos), cit. (n. 2), p. 106.

${ }^{33}$ Anay a, James S., Los pueblos indigenas en el Derecho internacional, cit. (n. 14), pp. 91 ss.; Rodríguez-PIÑero Royo, Luis, Pueblos indígenas y Derecho internacional: 
declaraciones internacionales dirigidas al reconocimiento del derecho a la autodeterminación se han entendido referidas a aquellos territorios sujetos a la administración colonial en ese momento histórico, es decir, a los restos del antiguo colonialismo europeo, y no así a subconjuntos de Estados ya desde hace mucho tiempo liberados de la carga formal de la dominación colonial; ii) por el otro, porque tales declaraciones estaban previstas para territorios en los que el pueblo que se hace sujeto de la autodeterminación constituye la mayoría de la población del espacio autodeterminado, y no una minoría dentro de una población más amplia que ya se autodetermina de manera suficiente. De ahí, por tanto, que los partidarios de este nuevo paradigma indigenista hayan propugnado la aparición de específicas Declaraciones de Derechos de los Pueblos Indígenas ${ }^{34}$ en los que se reconozca a estos inequívocamente la categoría de sujeto de ese derecho colectivo a la libre determinación, en tanto que mayoría o, en todo caso, minoría cualificada en el seno de Estados ya constituidos ${ }^{35}$. Es este el modelo al que apuntan las últimas reformas constitucionales en América Latina, en países como Ecuador (1978 y 2008), Guatemala (1985), Nicaragua (1987), Brasil (1988), Colombia (1991), Paraguay (1992), México (1992 y 2001), Perú (1993), Bolivia (1994 y 2009) y Venezuela (1999) ${ }^{36}$. Ahora bien, con independencia de la justicia o injusticia de este programa (de hecho los partidarios del indigenismo no consideran suficientes las reformas constitucionales emprendidas en la línea del reconocimiento de los derechos de los pueblos indígenas, en la medida en que suponen, a su juicio, más bien una vuelta al pasado colonial -frente al neocolonialismo de los Estados decimonónicos- puesto que la lengua castellana sigue gozando de un privilegio ilegítimo, el desarrollo de los espa-

una historia incómoda, en GIRAudo, Laura (editora), Ciudadania y derechos indígenas en América Latina, cit. (n. 12), pp. 83-105.

${ }^{34}$ En concreto, la Declaración de derechos de personas pertenecientes a minorías nacionales o étnicas (Resolución de la Asamblea General de las Naciones Unidas $\mathrm{N}^{\circ}$ 47/135, de 18 de diciembre de 1992) y, sobre todo, la Declaración sobre los derechos de los pueblos indígenas (Resolución de la Asamblea General de las Naciones Unidas A/ Res/61/295, de 13 de septiembre de 2007), con antecedentes en los Convenios No 107 (1957) y 169 (1989) de la OIT. Sobre el tema, con detalle, últimamente: Allen, Stephen - Xanthaki, Alexandra (editores), Reflections on the UN Declaration on the Rights of Indigenous Peoples (Oxford, 2011).

${ }^{35}$ Anaya, James S., cit. (n. 14), pp. 135 ss.

${ }^{36}$ Véase al respecto: Clavero, Bartolomé, Derecho indigena y cultura constitucional en América (México D. F., 1994); últimamente, Martínez Bringas, Asier, Naturaleza de la(s) autonomía(s) indigena(s) en el marco de la Constitución boliviana. Una reflexión sobre el contenido de los derechos indígenas, en Revista General de Derecho Público Comparado, 9 (2011) [www.iustel.com]; más crítico al respecto: CoNTRERAS Peláez, Francisco Javier, Los derechos indigenas en las nuevas constituciones hispanoamericanas, en Derechos y Libertades, 26 (2012), pp. 83-107. 
cios de autodeterminación de los pueblos indígenas se deja en manos de la ley estatal -es decir, la impuesta por la parte no indígena- y, además, solo se concede espacio al Derecho indígena sustantivo - las costumbres - pero no a la capacidad de ejecución jurisdiccional del mismo, que queda en manos de los tribunales estatales), el problema mayor que aquí se debate es la aceptabilidad o no de una consideración de ese derecho a la libre determinación de tales pueblos (en el seno de Estados de Derecho legítimamente constituidos y con principios democráticos) como un verdadero derecho de carácter colectivo que debe dar lugar a un nuevo modelo constitucional de carácter federal que responda a las exigencias del multiculturalismo ${ }^{37}$. Dos graves objeciones pueden plantearse, a nuestro juicio, ante esta consideración:

$1^{\circ} \mathrm{Tal}$ solución lesionaría gravemente el principio de igualdad. Los derechos constitucionales en el marco del Estado (democrático) de Derecho se fundan en el igualitarismo político, porque esa es la única forma de garantizar un óptimo de libertad para todos los miembros de la comunidad política. La consideración diferenciada de los individuos en función de su adscripción a una u otra comunidad cultural en el seno de la comunidad política conlleva la existencia de diferentes esferas de libertad para los distintos miembros del grupo en función de su pertenencia a un subconjunto del mismo, lo que implica tanto la posible reducción de las libertades de los miembros individualizados de tal subconjunto como un grave riesgo de ruptura de la propia comunidad política.

$2^{\circ}$ Ese planteamiento supone la supeditación de las mayorías a los criterios de las minorías (al menos, donde los pueblos indígenas sean propiamente minoritarios). La ley como expresión de la voluntad general debe ceder el paso ante formas de creación del Derecho que no responden a parámetros de medición objetivos, sino variables en función de coordenadas cualitativas incontrastables. Ello trae como consecuencia, como en el caso anterior, una ruptura de un elemento constructivo esencial de la comunidad política organizada como Estado de Derecho, que exige el imperio de la ley discutible en el espacio público como pieza fundamental de garantía de la libertad de los ciudadanos y su seguridad jurídica.

No podemos entrar a discutir aquí estas cuestiones con detalle, pero lo que sí parece claro es que la lectura de la historia hace pensar que las recientes reformas constitucionales en la línea de un mayor reconocimiento de los "derechos colectivos" de los pueblos indígenas en los Estados iberoamericanos, en la medida en que estas se han operado, no suponen necesariamente un progreso en la ampliación de los derechos de libertad de los ciudadanos,

${ }^{37}$ Herrero de Miñón, Miguel, Autodeterminación y derechos históricos, en Herrero de Miñón, Miguel - Lluch, Ernest (editores), cit. (n. 2), pp. 211-219. 
como cabría esperar de cualquier proceso democrático, sino más bien el retorno a fórmulas del pasado en la articulación jurídica que recuerdan vivamente a las de la época colonial. Al colonialismo encubierto con fórmulas constitucionales de las Constituciones de la Emancipación le ha sucedido un neocolonialismo postmoderno que, en nombre del respeto a los derechos tribales frente a los ciudadanos, puede conducir a un regreso de formas de sumisión y sujeción personal de los individuos concretos pertenecientes a esos pueblos que tal vez deberían considerarse superadas.

\section{BiBLIOGRAFÍA}

Acosta, José de, De procuranda Indiorum salute (Salamanca, 1588) (ed. L. Pereña Abril y otros, Madrid, 1984).

Allen, Stephen - Xanthaki, Alexandra (editores), Reflections on the UN Declaration on the Rights of Indigenous Peoples (Oxford, 2011).

Almario García, Óscar, Del nacionalismo americano en las Cortes de Cádiz al independentismo y nacionalismo de Estado en la Nueva Granada, 1808-1821, en Chust, Manuel - Fraseuet, Ivana (editores), Los colores de las independencias iberoamericanas. Liberalismo, etnia y raza (Madrid, 2009).

Álvarez Cuartero, Izaskun, Hacer patria sin indios. De los sanjuanistas a la guerra de castas, 1812-1847, en Chust, Manuel - FrasQuet, Ivana (editores), Los colores de las independencias iberoamericanas. Liberalismo, etnia y raza (Madrid, 2009).

Amry, René Paul, Defensa cultural y pueblos indigenas: propuestas para la actualización del debate, en Hurtado Pozo, José (director), Derecho penaly pluralidad cultural, en Anuario de Derecho Penal 2006 (Lima, 2007).

Anaya, James S., Los pueblos indigenas en el Derecho internacional (Madrid, 2005).

ANSUÁtegui Roig, Francisco Javier (editor), Una discusión sobre los derechos colectivos (Madrid, 2001).

Barrientos Grandón, Javier, Historia del Derecho indiano del Descubrimiento colombino a la Codificación, I: Ius commune - ius proprium en las Indias Occidentales (Roma, 2000).

Burrus, Ernest J. (editor), The Writings of Alonso de la Vera Cruz, II: Defense of the Indians: Their Rights (Rome St. Louis, Mo., 1968).

Cabedo Mallol, Vicente, Pluralismo jurídico y pueblos indigenas (Barcelona, 2012).

Chust, Manuel (coordinador), Doceañismos, constituciones e independencias. La Constitución de 1812 y América (Madrid, 2006).

Chust, Manuel, La Constitución de 1812: una revolución constitucional bihemisférica, en Annino, Antonio - Ternavasio, Marcela (coordinadores), El laboratorio constitucional iberoamericano: 1807/1808-1830 (Madrid - Frankfurt am Main, 2012).

Clavero, Barcelona, Multiculturalismo y monoconstitucionalismo de lengua castellana en América, en El mismo, "Happy Constitution". Cultura y lengua constitucionales (Madrid, 1997).

Clavero, Bartolomé, Ama Llunku, Abya Yala: Constituyencia Indigenay Código Ladino por América (Madrid, 2000).

Clavero, Bartolomé, Constituciones y pueblos entre Cádizy México, Europa y América, 
en Clavero, Bartolomé - Portillo, José María - Lorente, Marta, Pueblos, nación, constitución (en torno a 1812) (Vitoria/Gasteiz, 2004).

Clavero, Bartolomé, Derecho indígena y cultura constitucional en América (México D. F., 1994).

Clavero, Bartolomé, Derechos humanos (individuales) y Derechos históricos (colectivos), en Herrero de Miñón, Miguel - Lluch, Ernest (editores), Derechos históricos y constitucionalismo útil (Barcelona, 2001).

Cruz Parcero, Juan Antonio, Sobre el concepto de derechos colectivos, en El Mismo, El lenguaje de los derechos. Ensayo para una teoria estructural de los derechos (Madrid, 2007).

Declaración de derechos de personas pertenecientes a minorias nacionales o étnicas (Resolución de la Asamblea General de las Naciones Unidas $\mathrm{N}^{\circ}$ 47/135, de 18 de diciembre de 1992).

Declaración sobre los derechos de los pueblos indígenas (Resolución de la Asamblea General de las Naciones Unidas A/Res/61/295, de 13 de septiembre de 2007).

Frasquet, Ivana, Orígenes del primer constitucionalismo mexicano, 1810-1824, en Annino, Antonio - Ternavasio, Marcela (coordinadores), El laboratorio constitucional iberoamericano: 1807/1808-1830 (Madrid - Frankfurt am Main, 2012).

GAREIS, Iris, 'República de indios' - 'República de españoles': reinterpretación actual de conceptos andinos coloniales, en Jahrbuch für Geschichte von Staat, Wirtschaft und Gesellschaft Lateinamerikas, 30 (1993).

GIRAUdo, Laura, Entre rupturas y retornos: la nueva cuestión indigena en América Latina, en La misma (editora), Ciudadanía y derechos indígenas en América Latina: poblaciones, estados y orden internacional (Madrid, 2007).

GonZÁlez Galván, Jorge Alberto, ElEstado, los indígenas y el Derecho (México, 2010).

Herrero de Miñón, Miguel, Autodeterminación y derechos históricos, en Herrero de Miñón, Miguel - LluCH, Ernest (editores), Derechos históricos y constitucionalismo útil (Barcelona, 2001);

Jones, Peter, Group Rights, en Zalta, Edward N. (editor), The Stanford Enciclopedia of Philosophy (2008) [http://plato.stanford.edu/entries/rights-group] (con amplia bibliografía internacional].

LeVaggi, Abelardo, República de indios y república de españoles en los reinos de Indias, en Revista de Estudios Histórico-Jurídicos., 23 (2001).

López CAlera, Nicolás, ¿Hay derechos colectivos? Individualidad y socialidad en la teoría de los derechos (Barcelona, 2000).

Lynch, John, The Spanish American Revolutions 1808-1826 (London, 1973).

Martínez Bringas, Asier, Naturaleza de la $(s)$ autonomia $(s)$ indígena $(s)$ en el marco de la Constitución boliviana. Una reflexión sobre el contenido de los derechos indigenas, en Revista General de Derecho Público Comparado, 9 (2011) [www.iustel.com]; más crítico al respecto: Contreras Peláez, Francisco Javier, Los derechos indígenas en las nuevas constituciones hispanoamericanas, en Derechos y Libertades, 26 (2012).

Martínez de BRINGas, Asier, Derechos humanosy diversidad(es) cultural(es). Los retos de la interculturalidad, en Derechos y Libertades, 26 (2012).

Martínez, Felicísimo - Mate, Reyes - Ruiz, Marcos R. (coordinadores), Pensar Europa desde América. Un acontecimiento que cambió el mundo (Barcelona, 2012).

Pagden, Anthony, La caida del hombre natural (1986, trad. esp. Madrid, 1988).

QuiJADA, Mónica, Estado nacional y pueblos originarios, entre la homogenización y la diversidad: ¿una pulsión colectiva duradera?, en GIRAudo, Laura (editora), 
Ciudadania y derechos indigenas en América Latina: poblaciones, estados y orden internacional (Madrid, 2007).

Quintero, Inés - Almazara, Ángel Rafael, Dos proyectos: un solo territorio. Constitucionalismo, soberanía y representación. Venezuela, 1808-1821, en ANNINo, Antonio - Ternavasio, Marcela (coordinadores), El laboratorio constitucional iberoamericano: 1807/1808-1830 (Madrid - Frankfurt am Main, 2012).

Ramos Santana, Alberto (editor), La Constitución de Cádiz y su huella en América (Cádiz, 2011).

Restrepo Piedrahita, Carlos, Las primeras constituciones politicas de Colombia y Venezuela, en Soberanes Fernández, José Luis (editor), El primer constitucionalismo iberoamericano (Madrid, $1992=$ AYER. 8, 1992).

Rodríguez-Piñero Royo, Luis, Pueblos indígenasy Derecho internacional: una historia incómoda, en Giraudo, Laura (editora), Ciudadania y derechos indígenas en América Latina: poblaciones, estados y orden internacional (Madrid, 2007).

Sánchez Domingo, Rafael, Las Leyes de Burgos y la doctrina jurídica de la Conquista, en Revista Jurídica de Castilla y León, 28 (2012) [descargable en: http://www.jcyl. es/junta/cp/boletin/Revista_Juridica_28.pdf].

Soberanes Fernández, José Luis, El primer constitucionalismo mexicano, en EL MISMO (editor), El primer constitucionalismo iberoamericano, cit.

Szaszdi León-Borja, István, Después de las Leyes de Burgos, en e-Legal History Review, 14 (2012).

ThiвAud, Clément, En busca de la república federal: el primer constitucionalismo en la Nueva Granada, en Annino, Antonio - Ternavasio, Marcela (coordinadores), El laboratorio constitucional iberoamericano: 1807/1808-1830 (Madrid - Frankfurt am Main, 2012).

VAN Young, Eric, Etnia, politica local e insurgencia en México, 1810-1821”, en CHUST, Manuel - FRASQUET, Ivana (editores), Los colores de las independencias iberoamericanas. Liberalismo, etnia y raza (Madrid, 2009).

VATtel, Emeric de, Le droit des gens ou Principes de la loi naturelle appliqués à la conduite et aux affaires des Nations et des Souverains (Londres, 1758), 2 vols.

Veracruz, Alonso de la, De dominio infidelium et iusto bello (ed. E. J. Burrus). 